\title{
Screening of Germplasm of Clusterbean [Cymopsis tetragonoloba (L.) Taub.] in the Hot-arid Climate of Rajasthan using GxE Interaction Parameters
}

\author{
Om Vir Singh*, Neelam Shekhawat, Kartar Singh and R. Gowthami \\ National Bureau of Plant Genetic Resources, Regional Station, Jodhpur, India \\ *Corresponding author
}

\section{A B S T R A C T}

\section{Keywords \\ Cluster bean, Hot arid climate, Accession $\mathrm{x}$ environment interaction, Crossover and non-crossover interactions, Regression analysis \\ Article Info \\ Accepted: \\ 10 June 2018 \\ Available Online: \\ 10 July 2018}

Thirty six accessions of cluster bean along with checks were screened during six seasons i.e. Summer and Kharif of the year 2012, 2013 and 2014 for seven quantitative traits and data were subjected to GxE interaction analysis using regression and crossover and noncrossover interactions parameters. Seven accessions IC 325800, IC 215046, IC 103304, IC 34344, IC 140786, IC 370468, and IC 370490 were identified to be promising using regression analysis, whereas eight accessions IC 140764, IC 34344, IC 370509, IC 215046, IC 140790, IC 369789, IC 140771, and IC 200742 against standard check RGC 936 were identified as potential ones by using crossover and non-crossover interactions concept. Of these accessions IC 34344 and IC 215046 have been identified as high yielding accessions having specific adaptability and responsiveness to specific environment both by regression analysis and crossover and non-crossover interactions concept.

\section{Introduction}

Clusterbean (Cyamopsis tetragonoloba (L.) Taub.), commonly known as guar, is a very important crop of arid and semi-arid regions. Its mainly grown in India and Pakistan. It is drought tolerant crop and tolerates high temperature. The seed of cluster bean contains about $24-36 \%$ gum in the endosperm. The crop is mainly grown during rainy season, but it can also be grown successfully during summer season under irrigated condition. However, the average yield of cluster bean in arid and semiarid region is very low as compared to its potential. The productivity can be significantly increased with development of high yielding varieties and improved cultivation technologies. In India there has not been any specific variety for the Summer season. However, a few varieties have been developed for the Summer season but they are not suitable for hot- arid climate. Thus, farmers grow the varieties of Kharif season in Summer season. To enhance productivity and production of cluster bean it is advocated that breeders should look for environment specific 
varieties which are capable of giving high yield. This becomes more important in case of arid grain legumes to breed for their responsiveness to specific environment. Breeders have not made any breakthrough in the breeding of cluster bean because of difficulty in making crosses as flower size of cluster bean is very small. Most of the varieties in cluster bean developed from the selection. National Bureau of Plant Genetic Resources, Regional Station Jodhpur has a wide range of collection of diversity of cluster bean. Therefore, present investigation was carried out over years during Summer and Kharif seasons in the hot- arid climate of Rajasthan to identify season specific accessions in cluster bean using regression analysis (Eberhart and Russell, 1966 and Perkins and Jinks, 1968) and cross and noncrossover interactions concept (Gail and Simon, 1985). Earlier information on this aspect in cluster bean germplasm is not available.

\section{Materials and Methods}

Thirty six diverse accessions collected in different years from different place in India along with best performing local checks i.e. RGC 936, RGC 1005 and RGC 986 were evaluated in a randomized block design with three replications over three years during Summer and Kharif seasons at Regional Station of National Bureau of Plant Genetic Resources, Jodhpur. Thus, evaluation was done broadly in six environments. In each environment plots consisted of four rows of 3 $\mathrm{m}$ length with row to row and plant to plant distances of 30 and $10 \mathrm{~cm}$., respectively. Recommended doses of $\mathrm{P}_{2} \mathrm{O}_{5} @ 25 \mathrm{~kg} / \mathrm{ha}$ and $\mathrm{N}_{2} @ 15 \mathrm{~kg} / \mathrm{ha}$ were also applied at the time of sowing. Recommended packages and practices were followed to raise good crop. The data were recorded on five randomly taken plants from middle rows of each plot in each environment on seed yield/plant ( $g$ ), biological yield/plant (g), number of seeds/pod (average of 10 randomly taken pods from each plant), number of pods per plant, number of branches per plant, number of pod per clusters per plant and 100-seed weight (g) and data were analyzed separately for each environment. Adjusted progeny means were used for the combined analysis and for the traits exhibiting the presence of $\mathrm{g} x \mathrm{e}$ interaction. Regression analysis and analysis to detect the presence of crossover and noncrossover interactions were carried out as per Eberhart and Russell (1966), Perkins and Jinks (1968) and Gail and Simon (1985).

\section{Results and Discussion}

Analysis of variance revealed significant differences among accessions for the seven traits in all six seasons. The combined analysis revealed the presence of $\mathrm{g} x$ e interaction for seed yield/plant $(\mathrm{g})$, biological yield/plant $(\mathrm{g})$, number of seeds/pod (average of 10 randomly taken pods from each plant), number of pods per plant, number of branches per plant, number of pod per clusters and 100-seed weight (g). Regression analysis enables breeders to select desirable accessions with respect to the responsiveness and stability in different environments. In the studied materials the accessions IC 370468, IC 325800, IC 103304, IC 140786, IC 370490, IC 34344 and IC 215046 had above average performance and responsiveness with respect to seed yield/plant using regression analysis (Table 1). Among these high yielding accessions IC 325800, IC 103304, IC 370468, IC 140786 and IC 370490 can be designated as stable ones with average responsiveness. Though the accessions IC 34344 and IC 215046 are above average yielder and also have shown above average responsiveness coupled with instability. Accession IC 34344and IC 215046 were highest yielder during Kharif 2013 and Kharif 2014 respectively followed by IC 370490 (Kh., 
2013), IC 370468 (Kh., 2014), IC 325800 and IC 103304 (Kh., 20112) and IC $140786(K h$. 2013) and were significantly superior to the best check RGC 936. The accession IC 34344 showed above average performance along with instability for seed yield per plant, biological yield/plant, 100-seed weight, number of pods per plant and number of branches per plant being the best performance of this accession for these traits again in Kharif 2013 and accession IC 215046 showed above average performance along with instability for seed yield per plant, biological yield/plant, number of pods per cluster, number of cluster per plant and number of branches per plant being the best performance of this accession for these traits again during Kharif 2014.

The regression technique describes the response pattern of individual accession without differentiating the kind of $g \mathrm{x} e$ interaction involving change in magnitude of response or direction among the accessions (Baker, 1988 and Virk and Mangat (1991). Baker (1988) described a test, which was initially proposed by Gail and Simon (1985) and illustrated its application to test the kind of interaction in crop plants. The concept of crossover and non-crossover interaction is important in decision making relating to crop improvement strategies (Baker, 1988), since the presence of crossover interaction is substantial evidence in favour of breeding for specific adaptation to certain situations. Baker (1988) further suggested that in the absence of crossover interaction there is little substance for argument in the favour of breeding for adaptation to specific environment. The accessions exhibiting crossover interaction against a standard variety can be said to have specific adaptability and can replace that standard variety in the specific environments.

The existence of prior scientific basis to explain crossover interaction is crucial (Peto,
1982). Thus, it is advantageous to define the varietal combinations among which one has to look for qualitative interaction in advance. There will be enormous multiplicity of all possible varietal pairs for detection of crossover interaction if there is no prior basis for comparison. Such a practice will greatly increase the experiment-wise error rate. In the present case the new accessions were therefore, compared with the best check RGC 936 for detection of crossover interaction since the aim was to find a suitable alternative to RGC 936.

The $\mathrm{H}$ (heterogeneity of response) and $\mathrm{Q}^{+}$and $\mathrm{Q}^{-}$(for the presence of crossover interaction) against the standard variety RGC 936 were estimated for all studied accessions for the traits exhibiting the presence of $\mathrm{g} \mathrm{x} e$ interaction, i.e., seed yield/plant (g), biological yield/plant (g), number of seeds/pod, number of pods per plant, number of branches per plant, number of pod per clusters per plant and 100 -seed weight $(\mathrm{g})$ and their significance was tested (Baker, 1984). The accession exhibiting either significant $\mathrm{H}$ or $\mathrm{Q}^{+}$and $\mathrm{Q}^{-}$are given in Table 2 . For seed yield/plant $\mathrm{H}$ was significant for the 34 accessions against RGC 936. The presence of crossover interaction was observed for twenty nine accessions, IC 200679, IC 34317, IC 140789, IC 370478, IC 200742, IC 34344, IC 140771, IC 310630, IC 140764, IC 39990, IC 370509, IC 13348, IC 215046, IC 140790, IC 103996, IC 369789, IC 369838, IC 140787, IC 105302, IC 140788, IC 200676, IC 200709, IC 200717, IC 200738, IC 200756, IC 329062, IC 102800, RGC 1005 and RGC 986 for seed yield/plant against RGC 936. The 27 accessions i.e. IC 140771, IC 200717, IC 200742, IC 103304, IC 39990, IC 370509, IC 140786, IC 13348, IC 102873, IC 370468, IC 34317, IC 34344, IC 310630, IC 325800, IC 215046, IC 140790, IC 103996, IC 369789, IC 369838, IC 140787, IC 200727, IC 105302, IC 140788, IC 200676, IC 200738, IC 102800 and IC 325819 exhibited the 
presence of crossover interaction for biological yield/plant. The 23 accessions exhibited the presence of crossover interaction for seeds/pod for the accessions namely, IC 103304, IC 105302, IC 200676, IC 39990, IC 370509, IC 140786, IC 102873,
IC 200679, IC 310630, IC 140764, IC 102800, IC 325819, IC 325800, IC 140790, IC 103996, IC 369789, IC 140787, IC 200727, IC 200709, IC 140771, IC 200756, IC 329062 and RGC 986.

Table.1 Heterogeneity $(\mathrm{H})$ test of response for the comparison of mean seed yield/plant $(\mathrm{g})$ against the standard variety RGC 936 along with $\mathrm{Q}^{+}$and $\mathrm{Q}^{-}$values for crossover interaction and adaptability parameters for the accessions

\begin{tabular}{|c|c|c|c|c|c|c|}
\hline \multirow[t]{2}{*}{ Accession } & \multicolumn{3}{|c|}{ Adaptability Parameters } & \multicolumn{3}{|c|}{ Against RGC 936} \\
\hline & $\mathrm{u}+\mathrm{d}_{\mathrm{i}}$ & $B_{i} \pm S E$ & $\sigma^{2} d_{i}$ & $\mathrm{H}$ & $\mathrm{Q}^{+}$ & $\mathrm{Q}^{-}$ \\
\hline IC 103304 & 10.87 & $0.16^{*} \pm 0.09$ & 0.12 & $72.35^{\#}$ & 39.48 & 78.66 \\
\hline IC 103996 & 8.75 & $-0.80^{*} \pm 0.11$ & $0.34 *$ & $63.05^{\#}$ & 42.94 & $91.77^{\$}$ \\
\hline IC 105302 & 8.91 & $0.15^{*} \pm 0.34$ & $0.22 *$ & $62.87^{\#}$ & $80.42^{\$}$ & 32.04 \\
\hline IC 140764 & 14.26 & $-0.85^{*} \pm 0.54$ & $0.18^{*}$ & $35.60^{\#}$ & 32.39 & $102.10^{\$}$ \\
\hline IC 140771 & 13.26 & $0.12^{*} \pm 0.32$ & $0.29 *$ & $28.74^{\#}$ & 64.78 & $43.96^{\$}$ \\
\hline IC 140786 & 10.55 & $-0.46^{*} \pm 0.27$ & 0.03 & $42.95^{\#}$ & 57.34 & 64.00 \\
\hline IC 140790 & 14.35 & $0.13^{*} \pm 0.25$ & $0.19^{*}$ & $39.18^{\#}$ & 99.76 & $65.17^{\$}$ \\
\hline IC 200717 & 8.70 & $0.25^{*} \pm 0.30$ & $0.38^{*}$ & $89.83^{\#}$ & 103.45 & $42.55^{\$}$ \\
\hline IC 200742 & 13.88 & $0.11^{*} \pm 0.03$ & $0.20^{*}$ & $37.86^{\#}$ & 58.75 & $64.29^{\$}$ \\
\hline IC 200756 & 8.95 & $0.53 * \pm 0.24$ & $0.64 *$ & $87.77^{\#}$ & 23.05 & $83.23^{\$}$ \\
\hline IC 215046 & 17.58 & $1.32 * \pm 0.08$ & $0.51^{*}$ & $55.14^{\#}$ & $73.74^{\$}$ & 27.93 \\
\hline IC 325800 & 11.00 & $0.09 * \pm 0.21$ & 0.07 & $93.53^{\#}$ & 53.28 & 99.76 \\
\hline IC 34344 & 16.44 & $1.29 * \pm 0.14$ & $0.27^{*}$ & $38.45^{\#}$ & 44.81 & $58.73^{\$}$ \\
\hline IC 369789 & 14.16 & $0.08^{*} \pm 0.20$ & $0.39^{*}$ & $89.48^{\#}$ & $46.64^{\$}$ & 87.56 \\
\hline IC 37490 & 9.57 & $0.23 * \pm 0.19$ & 0.13 & $100.31^{\#}$ & 65.06 & $99.84^{\$}$ \\
\hline IC 370468 & 12.58 & $0.45^{*} \pm 0.08$ & 0.16 & $59.80^{\#}$ & 61.88 & 91.87 \\
\hline IC 370509 & 14.53 & $-0.39 * \pm 0.23$ & $0.30^{*}$ & $37.34^{\#}$ & 43.35 & $102.63^{\$}$ \\
\hline IC 39990 & 8.96 & $0.83^{*} \pm 0.18$ & $0.66^{*}$ & $86.85^{\#}$ & 30.67 & $71.95^{\$}$ \\
\hline Grand Mean & $=0.94$ & & & & & \\
\hline RGC 936 & \pm 1.45 & & & & & \\
\hline
\end{tabular}

- Significant at $\mathrm{P}<0.05$; \# $\mathrm{H}$ was significant against $\mathrm{x}^{2} 0.05$ at $\mathrm{s}-1 \mathrm{df}$, where $\mathrm{s}$ is the number of environments. \$ minimum of either $\mathrm{Q}^{+}$or $\mathrm{Q}^{-}$was significant against "e" value given by Gail and Simon (1985). 
Table.2 Accessions exhibiting significant *, \#H (heterogeneity of response), and $\mathrm{Q}^{+}$and $\mathrm{Q}^{-}$ against standard variety RGC 936

\begin{tabular}{|c|c|c|}
\hline Characters & $\mathbf{H}$ & $\mathbf{Q}^{+}$and $\mathbf{Q}^{-}$ \\
\hline Seed yield/plant (g) & $\begin{array}{l}\text { All accessions } \\
\text { except IC } \\
325819 \text { and IC } \\
200727\end{array}$ & $\begin{array}{l}\text { IC } 200679 \text {, IC } 34317 \text {, IC } 140789 \text {, IC } 370478 \text {, IC } 200742 \text {, } \\
\text { IC } 310630 \text {, IC } 140764 \text {, IC } 39990 \text {, IC } 370509 \text {, IC } 13348 \text {, IC } \\
34344 \text {, IC } 140771 \text {, IC } 215046 \text {, IC } 140790 \text {, IC } 103996 \text {, IC } \\
369789 \text {, IC } 369838 \text {, IC } 140787 \text {, IC } 105302 \text {, IC } 140788 \text {, IC } \\
\text { 200676, IC } 200709 \text {, IC } 200717 \text {, IC } 200738 \text {, IC } 200756 \text {, IC } \\
\begin{array}{l}329062 \text {, IC } 102800, \text { RGC } 1005 \text { and RGC } 986 \text { (28 } \\
\text { accessions) }\end{array}\end{array}$ \\
\hline $\begin{array}{l}\text { Biological yield/ plant } \\
\text { (g) }\end{array}$ & $\begin{array}{lr}\text { All accessions } \\
\text { except } & \text { IC } \\
329062 & \text { IC } \\
200679 & \end{array}$ & $\begin{array}{l}\text { IC } 140771 \text {, IC } 200717 \text {, IC } 200742 \text {, IC } 103304 \text {, IC } 39990 \text {, IC } \\
370509 \text {, IC } 140786 \text {, IC } 13348 \text {, IC } 102873 \text {, IC } 370468 \text {, IC } \\
34317 \text {, IC } 34344 \text {, IC } 310630 \text {, IC } 325800 \text {, IC } 215046 \text {, IC } \\
140790 \text {, IC } 103996 \text {, IC } 369789 \text {, IC } 369838 \text {, IC } 140787 \text {, IC } \\
200727 \text {, IC } 105302 \text {, IC } 140788 \text {, IC } 200676 \text {, IC } 200738 \text {, IC } \\
102800 \text { and IC } 325819,(27 \text { accessions) }\end{array}$ \\
\hline Number of seeds/pod & $\begin{array}{l}\text { All accessions } \\
\text { except } \quad \text { IC } \\
200738, \text { IC } \\
13348 \text { and } \text { IC } \\
369838\end{array}$ & $\begin{array}{l}\text { IC } 103304 \text {, IC } 105302 \text {, IC } 200676 \text {, IC } 39990 \text {, IC } 370509 \text {, IC } \\
140786 \text {, IC } 102873 \text {, IC } 200679 \text {, IC } 310630 \text {, IC } 140764 \text {, IC } \\
\text { 102800, IC } 325819 \text {, IC } 325800 \text {, IC } 140790 \text {, IC } 103996 \text {, IC } \\
369789 \text {, IC } 140787 \text {, IC } 200727 \text {, IC } 200709 \text {, IC } 140771 \text {, IC } \\
\text { 200756, IC } 329062 \text { and RGC } 986 \text { ( } 23 \text { accessions). }\end{array}$ \\
\hline No. pods /plant & $\begin{array}{lr}\text { All accessions } \\
\text { except } & \text { IC } \\
103996, & \text { IC } \\
329062 & \end{array}$ & $\begin{array}{l}\text { IC } 140790 \text {, IC } 200756 \text {, IC } 369789 \text {, IC } 369838 \text {, IC } 140787 \text {, } \\
\text { IC } 200727 \text {, IC } 200676 \text {, IC } 310630 \text {, IC } 140764 \text {, IC } 325800 \text {, } \\
\text { IC } 103304 \text {, IC } 39990 \text {, IC } 370509 \text {, IC } 13348 \text {, IC } 370468 \text {, IC } \\
34317 \text {, IC } 200709 \text {, IC } 140771 \text {, IC } 200717 \text {, IC } 200738 \text {, IC } \\
102800 \text {, IC } 325819 \text { (22 accessions) }\end{array}$ \\
\hline No. of branches/ plant & $\begin{array}{l}\text { All accessions } \\
\text { except } \quad \text { IC } \\
310630, \quad \text { IC } \\
140764 \text { and } \text { G- } \\
492\end{array}$ & 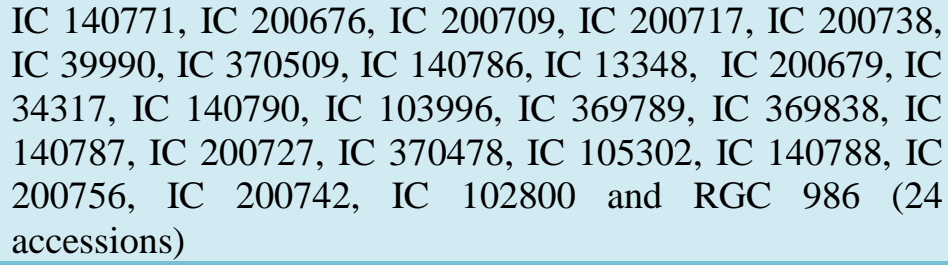 \\
\hline No. of pods/ cluster & $\begin{array}{l}\text { All accessions } \\
\text { excepts } \quad \text { IC } \\
370478, \quad \text { IC } \\
105302, \quad \text { IC } \\
140788, \text { and } \\
370468\end{array}$ & $\begin{array}{l}\text { IC } 102800 \text {, IC } 325819 \text {, IC } 13348 \text {, IC } 102873 \text {, IC } 200676 \text {, IC } \\
200709 \text {, IC } 140771 \text {, IC } 200742 \text {, IC } 310630 \text {, IC } 140764 \text {, IC } \\
325800 \text {, IC } 103304 \text {, IC } 39990 \text {, IC } 34317 \text {, IC } 215046 \text {, IC } \\
140790 \text {, IC } 103996 \text {, IC } 369789 \text {, IC } 369838 \text {, IC } 140787 \text {, IC } \\
200727 \text {, IC } 200738 \text {, IC } 200756 \text {, IC } 329062 \text { (24 accessions) }\end{array}$ \\
\hline 100-seed weight (g) & $\begin{array}{lr}\text { All accessions } \\
\text { except } & \text { IC } \\
13348, & \text { IC } \\
102873 \text { IC } \\
34317 \text { IC } \\
200717 \text { and } & \text { IC } \\
200756 & \end{array}$ & $\begin{array}{l}\text { IC } 140788 \text {, IC } 370468 \text {, IC } 200679 \text {, IC } 140790 \text {, IC } 370478 \text {, } \\
\text { IC } 103996 \text {, IC } 369838 \text {, IC } 140787 \text {, IC } 200727 \text {, IC } 105302 \text {, } \\
\text { IC } 200676 \text {, IC } 200709 \text {, IC } 102800 \text {, IC } 140764 \text {, IC } 325800 \text {, } \\
\text { IC } 103304, \text { IC } 39990, \text { IC } 370509 \text {, IC } 140786 \quad(19 \\
\text { accessions). }\end{array}$ \\
\hline
\end{tabular}

*H was significant against $\mathrm{x}^{2} 0.05$ at s-l df, where $\mathrm{s}$ is the number of environments. \# minimum of either $\mathrm{Q}^{+}$or $\mathrm{Q}$ was significant against "C" value given by Gail and Simmons (1985). 
The presence of cross over interaction showed by the 22 accessions namely; IC 140790, IC 200756, IC 369789, IC 369838, IC 140787, IC 200727, IC 200676, IC 310630, IC 140764, IC 325800, IC 103304, IC 39990, IC 370509, IC 13348, IC 370468, IC 34317, IC 200709, IC 140771, IC 200717, IC 200738, IC 102800 and IC 325819 for number of pods per plant. The 24 accessions had the presence of cross over interaction for number of branches per plant were IC 140771, IC 200676, IC 200709, IC 200717, IC 200738, IC 39990, IC 370509, IC 140786, IC 13348, IC 200679, IC 34317, IC 140790, IC 103996, IC 369789, IC 369838, IC 140787, IC 200727, IC 370478, IC 105302, IC 140788, IC 200756, IC 200742, IC 102800 and RGC 986. The 24 accessions namely; IC 102800 , IC 325819, IC 13348, IC 102873, IC 200676, IC 200709, IC 140771, IC 200742, IC 310630, IC 140764, IC 325800, IC 103304, IC 39990, IC 34317, IC 215046, IC 140790, IC 103996, IC 369789, IC 369838, IC 140787, IC 200727, IC 200738, IC 200756 and IC 329062 expressed the presence of cross over interaction for number of pods per cluster. The 19 accessions i.e IC 140788, IC 370468, IC 200679, IC 140790, IC 370478, IC 103996, IC 369838, IC 140787, IC 200727, IC 105302, IC 200676, IC 200709, IC 102800, IC 140764, IC 325800, IC 103304, IC 39990, IC 370509, IC 140786 showed the presence of cross over interaction for test weight. However, most of the accessions expressed the presence of crossover interaction but all accessions failed to exhibit crossover interaction for all traits against RGC 936 thus, presence or absence of crossover interaction was accession specific and trait specific (Rathore and Gupta 1995).

The accession IC 200742, IC 215046, IC 103190, IC 140764 and IC 34344 in Kharif 2014; and IC 140790. IC 370509, IC 103996 and IC 140771, had significantly higher seed yield/plant than check RGC 936 during kharif 2013.
The conclusion drawn from regression analysis and crossover and non-crossover interactions concept about identifying accessions having specific adaptability differs considerably. The accessions IC 370468, IC 325800, IC 103304, IC 140786, IC 34344 and IC 215046 identified as potential yielder having specific adaptability on the basis of regression analysis failed to exhibit significant $\min \left(\mathrm{Q}^{+}\right.$or $\left.\mathrm{Q}^{-}\right)$against standard variety RGC 936 except IC 34344and 103300 which had significant $\min \left(\mathrm{Q}^{+}, \mathrm{Q}^{-}\right)$against RGC 936. On the other hand the nine accessions IC 140790. IC 370509, IC 103996, IC 140771, IC103190, IC 200756, IC 140764 IC 34344and IC 215046 were identified as potential yielders having specific adaptability on the basis of crossover and non-crossover interaction concept, failed to exhibit stable above average performance and responsiveness for seed yield/plant except IC 34344 and IC 215046.

A mention may be made of the accessions, IC 34344and IC 215046, which have been identified as a high yielding ones having specific adaptability both by using regression analysis and crossover and non-crossover interaction concepts. These accessions gave significantly more mean seed yield/plant than the standard variety RGC 936. However during 2013 these had insignificant lower seed yield than RGC 936 Thus, accession IC 34344and IC 215046 had specific adaptation rather than possessing general adaptation (Sharma, 1995).

\section{References}

Virk, D. S. and B. K. Mangat (1991). Detection of crossover accession $\mathrm{x}$ environment interaction in pearlmillet. Euphytica., 52: 193-199.

Perkins, J. M. and J. L. Jinks (1968). Environmental and accessionenvironmental components of variability IV. Non-linear interaction 
for multiple inbred lines. Heredity., 23: 525-535.

Gail, M. and R. Simon (1985). Testing for quantitative interaction in Schizophyllum commune. analysis and character. Heredity., 27: 361-372.

Rathore, P. K. and V. P. Gupta (1995). Crossover and noncrossover interactions and regression analysis for seed yield and its components in pea. Crop Improv., 21: 14-18.

Baker, R. J. (1988). Test for crossover accession-environment interaction.
Can. J. Plant SeL, 68 (4): 405-410.

Sharma, R. K. (1995). Breeding lentil for response to additional nitrogen application. Crop Improv., 22: 139141.

Peto, R. (1982). Statistical aspects of cancer trials. pp. 867-871. In: E. E. Halnan (ed.), Treatment of cancer. Chapman and Hall, London, U.K.

Eberhart, S. A. and W. A. Russell (1966). Stability parameters for comparing varieties. Crop Sci., 6: 36-40.

\section{How to cite this article:}

Om Vir Singh, Neelam Shekhawat, Kartar Singh and Gowthami, R. 2018. Screening of Germplasm of Clusterbean [Cymopsis tetragonoloba (L.) Taub.] in the Hot-arid Climate of Rajasthan using GxE Interaction Parameters. Int.J.Curr.Microbiol.App.Sci. 7(07): 1553-1559. doi: https://doi.org/10.20546/ijcmas.2018.707.183 